\title{
1986-2017 年呼伦湖湖冰物候特征变化
}

\author{
吴其慧, 李畅游, 孙 标“, 史小红, 赵胜男, 韩知明 \\ (内蒙古农业大学水利与土木建筑工程学院, 呼和浩特 010018)
}

\begin{abstract}
摘 要: 湖冰冰情物候特征是气候变化的敏感指示器之一。论文以呼伦湖为研究对象, 基于 MODIS、Landsat、GF1、HJ-1 等多源遥感影像及气象数据, 利用 RS 和 GIS 技术综合分析了 1986-2017 年呼伦湖冰情物候特征及其对区 域气候的响应。结果表明: (1) 呼伦湖年均开始冻结时间在 10 月下旬至 11 月上旬, 从结冰开始到完全封冻的时间 平均只有 $6.4 \mathrm{~d}$; 开始融冰时间在次年的 4 月上旬, 消融期平均为 $32 \mathrm{~d}$ 左右, 到 5 月初或 5 月上旬湖冰完全融化。(2) 1986-2017年,在整个研究期呼伦湖完全封冻期呈现显著缩短趋势, 平均缩短 $18.5 \mathrm{~d}$; 完全结冰时间有一定延迟现 象, 平均延后 $8.4 \mathrm{~d}$; 冰全部融化时间呈现提前趋势, 平均提前了 $11.2 \mathrm{~d}$ 。(3) 湖冰冻结消融空间特征表现不同, 冻结 时先从湖岸形态较复杂地区结冰, 然后由东岸向西岸迅速封冻, 消融时先从湖泊西北岸开始, 逐渐向东岸融化。

(4) 在影响因素方面,呼伦湖冰情特征主要受到区域气温、风速、风向等因素的影响。
\end{abstract}

关 键 词: 湖冰; 多源遥感; 时空变化;物候; 呼伦湖

目前全球气候变化造成的环境影响较大,备受 国内外科研学者的关注(秦大河, 2012), 全球环境变 化因区域不同存在差异(Stocker et al, 2014)。相关 研究表明气候变化对地球自然生态系统有直接影 响, 气候暖化对于寒区的影响主要表现在冰川消融 状态明显以及湖冰冻融时间变化异常等(Pachauri $\mathrm{R}$, et al, 2014), 此类变化对地球生态环境有着明显 的影响(Hodgkins et al, 2002; Weber et al, 2016)。湖 泊作为区域内重要生态系统, 对于区域气候变化所 带来的影响有着敏感的响应, 尤其在冰情方面, 更 是与气候变化联系紧密(车涛等, 2009)。

目前, 湖冰研究主要集中在时间、属性等参数 的提取分析, 前者主要包括湖泊的冻结消融时间, 后者通常包括冰厚、冰体类型等。国外关于湖冰的 研究主要集中在北美、北欧与加拿大等地区(Howell et al, 2009; Cheng et al, 2013), 研究内容包括湖
冰物候特征的分析、湖冰与气候变化间的关系 (Weyhenmeyer et al, 2012), 以及利用相关模型模拟 湖冰演变过程等(Magnuson et al, 2000; Duguay et al, 2010)。研究表明湖冰冻融过程对气候变化有较 高的响应。Benson等(2012)对北美境内的众多湖泊 进行了长时间序列的研究, 结果显示, 每 $10 \mathrm{a}$ 尺度 上完全结冰时间平均滞后 $1.6 \mathrm{~d}$, 且完全消融时间平 均提前 $1.9 \mathrm{~d}$, 并得出气温对湖泊的封冻时间和周期 有一定关系。Latifovic 等(2007)对比分析了 19752004 年与 1846 - 1995 年明尼苏达州和纽约的 65 个 湖泊的冰情信息后, 得出该地的湖泊随时间的增 加, 结冰日期都有推迟、而消融日期却有提前的现 象。国内学者在湖冰方面研究开展较晚, 且主要集 中于青藏高原区域。如Cai等(2019)利用MODIS 影 像对青藏高原区域内 2001-2017年 58 个湖泊的冰 情进行研究, 发现地理位置和气候条件决定了冰情

收稿日期: 2018-08-27; 修订日期: 2019-06-06。

基金项目: 国家自然科学基金项目(51869020,51779118); 内蒙古自然科学基金项目(2017BS0510)。 [Foundation: National Natural Science Foundation of China, No. 51869020 and 51779118; Natural Science Foundation of Neimenggu Province, No. 2017BS0510. ]

第一作者简介: 吴其慧(1992-), 男, 内蒙古包头人, 硕士生, 主要从事从事于湖冰遥感及湖泊水质的研究。 E-mail:WQHeart@126.com

*通信作者简介:孙标 $(1983-)$, 男, 内蒙古商都人, 助理研究员, 主要从事水资源与水环境研究。E-mail: sunbiao@imau.edu.cn

引用格式: 吴其慧, 李畅游, 孙标, 等. 2019. 1986-2017 年呼伦湖湖冰物候特征变化 [J]. 地理科学进展, 38(12): 1933-1943. [Wu Q H, Li C Y, Sun B, et al. 2019. Change of ice phenology in the Hulun Lake from 1986 to 2017. Progress in Geography, 38(12): 1933-1943. ] DOI: $10.18306 /$ dlkxjz.2019.12.009 
特征的空间异质性, 且物理化学特征是直接影响湖 泊冻融情况的因素。祁苗苗等(2018)结合 Terra MODIS 和 Landsat TM/ETM+遥感影像对 20002016年青海湖冰情特征进行了分析, 发现青海湖封 冻期在 2000-2005 年和 2010-2016 年呈缩短趋 势, 且该区域冬半年的负积温是影响封冻期的关键 要素。王智颖等(2017)对青藏高原面积大于 100 $\mathrm{km}^{2}$ 的湖泊进行了研究, 分析了 2000-2015 年的变 化趋势, 发现北部湖区开始结冰期早, 完全融化期 晚, 封冻期长; 南部湖区开始结冰期晚, 完全融化期 早, 封冻期短, 且冰情特征主要受温度、降水、风速 等的影响。勾鹏等(2015)对 2000-2013 年纳木错 湖冰冰情进行了分析, 发现 2000 年后湖冰封冻时间 明显滞后, 消融时间明显提前, 且冰期不稳定。姚 晓军等(2015)对 2000-2011 年可可西里地区的湖 冰变化趋势进行了研究, 发现湖冰物候特征是区域 气候变化和湖泊自身条件共同作用的结果。

呼伦湖为内蒙古地区最大湖泊, 且流域面积广 阔, 气候变化对湖泊的影响较为明显, 故可作为该 地区气候变化研究的理想地点。在冰情方面,由于 地处中纬度寒旱区, 冰情较为复杂, 目前尚无人员 对其冰情特征进行研究, 本文基于多源遥感卫星影 像, 结合 RS 与 GIS 等相关技术手段, 分析研究 1986-2017 年的呼伦湖冰情变化特征与冻结消融 的时空变化过程, 并结合相关影响因素对呼伦湖湖 冰与气候变化之间的关系进行研究。

\section{1 研究区概况}

呼伦湖, 又称达秉湖, 为中国第五大淡水湖、东 北第一大湖, 位于呼伦贝尔草原西部新巴尔虎右 旗、新巴尔虎左旗与扎春诺尔之间,介于 $117^{\circ} 00^{\prime} 10^{\prime \prime}$ $\sim 117^{\circ} 41^{\prime} 40^{\prime \prime} \mathrm{E} 、 48^{\circ} 30^{\prime} 40^{\prime \prime} \sim 49^{\circ} 20^{\prime} 40^{\prime \prime} \mathrm{N}$ 。呼伦湖形似 斜长方形且不规则, 湖体呈西南偏东北方向, 湖整 体长 $93 \mathrm{~km}$, 最宽处为 $41 \mathrm{~km}$, 平均宽度 $25 \mathrm{~km}$, 湖周 长 $447 \mathrm{~km}$ (孙标, 2010; 韩知明等, 2017; 吴其慧, 2018), 如图 1 所示。据 2014年 5 月 30 日调查统计, 湖泊面积为 $2043 \mathrm{~km}^{2}$ 。呼伦湖流域覆盖了国内和 蒙古部分, 在中国部分的面积约占 3.8 万 $\mathrm{km}^{2}$ 。湖泊 面积近十几年起伏较大, 2003-2009年明显萎缩 (Zhang, 2013), 之后有所回升, 湖面水位最高时海拔 $545.59 \mathrm{~m}$; 平均水深 $5.7 \mathrm{~m}$, 最大水深 $8 \mathrm{~m}$ 左右, 蓄水 量为 138.5 亿 $\mathrm{m}^{3}$; 湖岸线弯曲系数为 1.88 (徐占江, 1989)。

\section{2 数据与方法}

\section{1 研究数据}

(1) 野外实测数据

为更好地研究呼伦湖冰情, 本文采用实测数据 与遥感数据相结合的方法对其进行研究。野外实 测数据来源于水环境保护与技术修复团队,团队从 2008 年至今每年进行 4 次实地采样观测并测量采 样数据, 分别在每年 1 月、 4 月、7-9 月、 11 月进行观 测并采样检测,包括湖冰冻融时间的观测, 该观测 数据主要与后期影像监测的湖泊结融冰时间进行 互补验证。气象数据来源于新巴尔虎右旗气象站 及呼伦湖西北岸的自动气象站(图 2)。

(2) 遥感数据

本文的遥感数据来源于 NASA 的 MODIS 影像 和 USGS 的 Landsat 系列影像, 以及来源于中国资源 卫星应用中心的高分辨率遥感卫星 GF-1 号和 HJ-1 号(表 1)。MODIS 影像文中选用L2级多光谱反射率

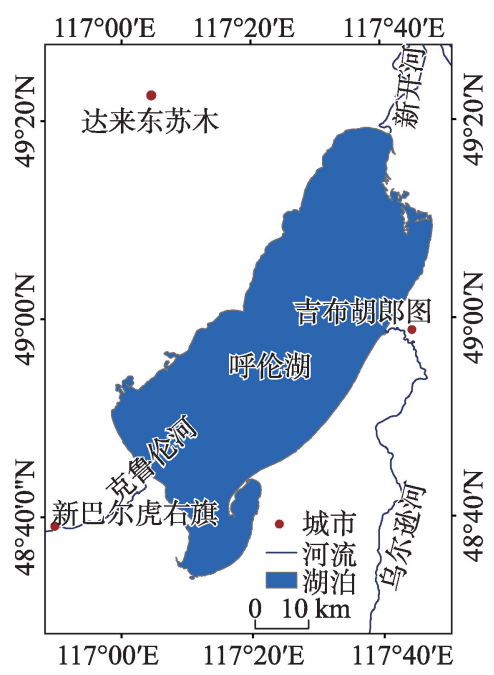

图 1 呼伦湖地理位置

Fig.1 Geographical location of the Hulun Lake
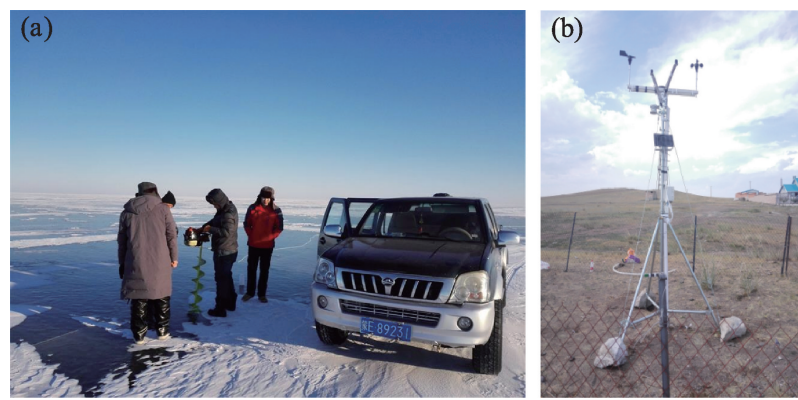

图 2 野外实地采样(a)及气象站布点(b)

Fig.2 Field sampling (a) and meteorological station (b) 
数据(MOD09GQ、MYD09GQ 与 MOD09GA、MYD 09GA)用来识别湖冰。Landsat 系列影像文中主要 使用Landsat 5、7、8 的遥感影像来提取识别湖冰。

GF-1 是中国自主研发的第一颗高分辨率遥感 卫星(白照广, 2013), 本文选择了 $16 \mathrm{~m}$ 分辨率的多 光谱数据, 该多光谱包含 4 个波段, 对识别湖冰有很 大帮助。HJ-1 是中国于 2008 年发射的灾害监测卫 星, 本文主要使用的是 $\mathrm{HJ}-1 \mathrm{~A} / \mathrm{B}$ 所搭载的 CCD 传感 器, 主要由于二者 $\mathrm{CCD}$ 相机设计原理相同, 且卫星 的轨道完全相同, 相位相差 $180^{\circ}$, 周期为 $4 \mathrm{~d}$ (王桥 等, 2010)。

\section{2 研究方法}

由于冰、水在不同波段的反射率不同, 水体的 反射率在可见光中的蓝绿光波段较高, 而在其他波 段的反射率则较低。自然环境中的水体在近红、中 红波段的反射率很低, 基本趋近于零 (殷青军等, 2005)。通常来说, 无任何杂质的冰反射率也很低, 然而自然界中, 河冰与湖冰因外界环境会含有其他 杂质以及产生大量气泡, 且冰面凹凸不平, 这样的 冰要比无其他杂质的纯净冰在可见光和近红外的 反射率要高很多(勾鹏等, 2015; 吴其慧, 2018)。本 文利用冰水光谱特性, 通过 MODIS、Landsat、HJ$1 \mathrm{~A} / \mathrm{B} 、 \mathrm{GF}-1$ 等多源遥感影像, 采用 2 种方法提取识 别湖冰。

\section{(1) 反射率國值法}

依据不同地物在不同波段的反射率不同, 采用 魏秋方等(2010)所用的波段计算公式计算, 该式利 用波段反射率差值与阈值来反演湖冰, 适用于 $\mathrm{MO}-$ DIS 影像, 本文所用的 MODIS 影像含有 2 个波段, 利用公式如下:

$$
\begin{gathered}
\text { Band } 1-\text { Band } 2>a \\
\text { Band } 1>b
\end{gathered}
$$

式中: Band1 和 Band2 分别对应 MODIS 影像的第 一和第二波段的反射率; $a 、 b$ 代表设定的阈值, 结合 GF-1 与 HJ-1 目视解译结果与反射率变化范围来确 定阈值, 本文选取 $a=0.03, b=0.05$, 即波段差值大于
0.03 且波段 1 的反射率大于 0.05 的像元为湖冰 (吴 其慧, 2018)。结果如图3a所示。

(2) NDSI指数法

归一化积雪指数(Normalized Difference Snow Index, NDSI)利用遥感影像中的绿光波段和短波红 外波段计算得到,该方法对于冰雪的识别有很高的 精度 (魏秋方等, 2010; Kour et al, 2015; 勾鹏等, 2015)。表达公式如下:

$$
\mathrm{NDSI}=\frac{\text { Band } 2-\text { Band5 }}{\text { Band } 2+\text { Band5 }}
$$

本文的 NDSI 方法主要基于 Landsat 系列遥感 影像来计算, 式中 Band2 和 Band5 分别代表 Landsat 5 和 7 影像中的第二和第五波段的反射率, 对于 Landsat 8 的影像则将式(3)中 Band2 和 Band5 分别 替换为 Landsat 8 中的 Band 3 和 Band6 来计算。根 据不同时期湖冰的反射率不同设定 NDSI 的阈值来 识别湖冰,结果如图 $3 \mathrm{~b}$ 所示。

结果表明, 上述 2 种方法对于湖冰的识别精度 较高(图 3), 方法一反射率國值法利用的是 MODIS 遥感影像, 由于 MODIS 空间分辨率为 $250 \mathrm{~m}$, 虽然 对于像呼伦湖这样的大型湖泊可以达到反演效果, 但影像经常受多云等天气干扰, 使得质量降低, 其 误差范围在 3 4 d。NDSI 指数法所利用的是 Landsat 系列的遥感影像,该卫星空间分辨率可达 $30 \mathrm{~m}$ 且所含波段较多, 虽然回归周期长, 但识别度高, 误 差大约在 $2 \mathrm{~d}$ 左右。所以本文主要利用 Landsat 系 列的遥感影像并使用指数法进行湖冰的提取识别, 并配合其他影像进行辅助判别, 以提高准确度。

通过分析多年影像来监测湖冰变化, 监测的冰 情特征包括初冰日、完全冻结日、开始消融日和完 全消融日。通过阅读文献, 采纳通用湖冰时间属性 定义,在文中定义如下: 初冰日(Freeze Onset, FO), 指通过遥感影像识别后, 当湖面首次有纯像元结冰 的现象出现并且结冰面积占湖体总面积 $5 \%$ 且可以 连续保持不消失的日期; 完全冻结日 (Complete Freeze Over, CFO), 指通过影像判别后, 当湖面上纯

表 1 遥感数据统计

Tab.1 Remote sensing data used in the study

\begin{tabular}{lllccccc}
\hline \multicolumn{1}{c}{ 遥感卫星 } & \multicolumn{1}{c}{ 传感器 } & 轨道号 & 空间分辨率/m & 回归周期/d & 过境时间 & 波段数 & 使用景数 \\
\hline Landsat & TM/ETM+/OLI & $124 / 26$ & 30 & 16 & & $7 \sim 11$ & 91 \\
TERRA/AQUA & MODIS & h25v04 & 250 & 1 & $10: 30 \mathrm{am}, 1: 30 \mathrm{pm}$ & 2 & 33 \\
GF-1 & $\mathrm{WFV}$ & $4 / 72$ & 16 & 2 & $10: 30 \mathrm{am}$ & 4 & 6 \\
HJ-1A/B & $\mathrm{CCD}$ & $9 / 52$ & 30 & 4 & $10: 30 \mathrm{am} \pm 30 \mathrm{~min}$ & 4 & 45 \\
\hline
\end{tabular}


(a) 反射率阈值法

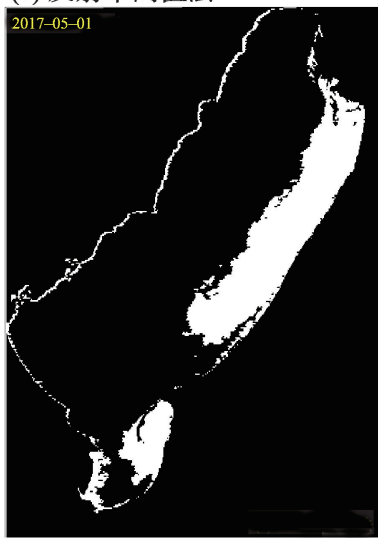

(b) NDSI指数法

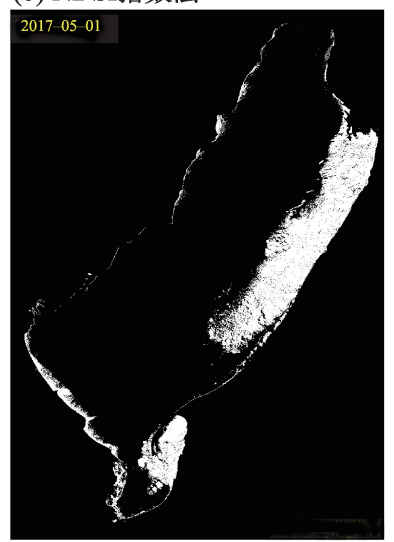

(c) GF-1目视解译

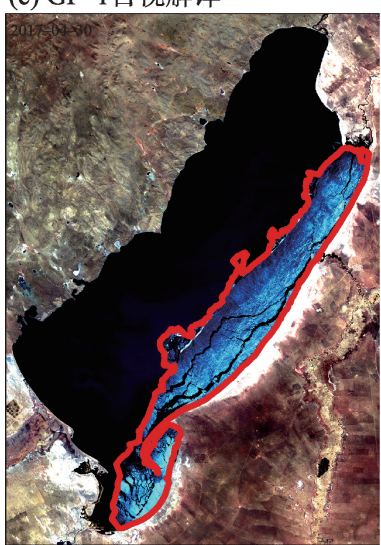

(d) HJ-1目视解译

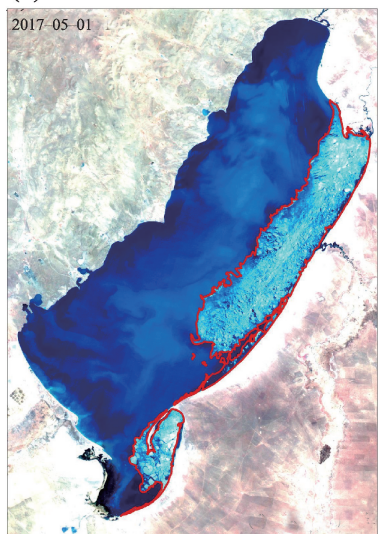

注:图 3a、3b 中白色为湖冰, 其他为黑色, 图 3c、3d 中红色线划区域为目视解译识别的湖冰。

图 3 不同方法的遥感影像湖冰识别

Fig.3 Identification of lake ice in remote sensing image based on different methods

像元全部被识别为冰状物且完全覆盖湖面的日期; 开始消融日(Melt Onset, MO), 指当湖面上整体覆盖 的冰首次出现纯像元断裂或消融的迹象, 而且能持 续以消融状态出现的日期; 完全消融日(Water Clear of Ice, WCI)即湖面上无任何像元被识别为冰 的日期。确定 4 个湖冰时间属性后, 可以得出其他 几个湖冰参数: 湖冰冻结期(Freeze Duration, FD)是 从初冰日起到完全冻结日止的时间段;湖冰完全封 冻期(Completely Freezing Duration, CFD) 是从完全 冻结日起到开始消融日止的时间段; 湖冰消融期 (Melt Duration, MD) 是从开始消融日起到完全消融 日止的时间段,湖冰存在期(Ice Existence Period, IEP) 是从初冰日起到完全消融日止的时间段 (Kropáček et al, 2013; 勾鹏等, 2015; 吴其慧, 2018)。具体见表 2 。

\section{3 结果与分析}

\subsection{6-2017 年呼伦湖湖冰变化特征}

依据多源遥感影像的反演与识别, 得到近 $30 \mathrm{a}$ 呼伦湖湖冰时间属性变化特征(表 2), 表 2 中采用年 积日法, 是从当年 1 月 1 日起开始计算的天数来记 录相关时间属性(如 10 月 25 日为年内第 297 天)。 造成湖冰识别误差的主要因素是由于遥感影像质 量难以保证, 当湖区出现暴风雪天气或云较多时会 对影像造成很大影响, 导致难以判别湖冰特征属 性。通过近 $30 \mathrm{a}$ 不同时间段各个冻融期湖冰时间 属性的分析得到以下结果。
呼伦湖冻结时间一般从每年 10 月下旬到 11 月 上旬开始,消融时间一般从 4 月中旬开始到 5 月上 中旬结束, 湖面年内有冰存在的时间平均为 $190 \mathrm{~d}$ 左右,整个湖面全部封冻的持续时间为 $154 \mathrm{~d}$ 左 右。从空间上看, 呼伦湖结冰过程是湖东岸最先结 冰, 然后迅速延伸到湖西岸, 直至全部封冻, 封冻的 时间非常短暂。湖冰融化状态则相反, 从湖西岸率 先消融, 然后向湖东岸逐渐融化。融冰的周期则相 对较长(吴其慧, 2018)。

本文统计了 1986-2017年的湖冰冻结消融参 数。呼伦湖平均初冰日 (FO) 为 10 月 30 日, 开始冻 结日期最早为 10 月 25 日,出现在 1986 年; 而最晚在 11 月 7 日, 出现在 2013 年。平均完全封冻日期为 11 月 6 日,完全冻结日期最早在 1986年的 10 月 29 日, 最晚出现在 2013 年的 11 月 15 日。呼伦湖平均开始 消融日期为 4 月 8 日,其中开始消融日期最早出现 在 2003 年的 4 月 3 日,最晚出现在 1987 年 4 月 19 日。平均完全融化日期为 5 月 9 日, 其中最早完全 融化日期出现在 2017 年 5 月 1 日,最晚出现在 1987 年的 5 月 21 日。1986-1987年间湖面完全封冻天 数达到 $173 \mathrm{~d}$, 为研究期内最长时间, 2013-2014年 间的封冻期只有 $143 \mathrm{~d}$, 为期间最少天数 (吴其慧, 2018)。

对相邻影像时间的阶段变幅取平均值,可以看 出,过去 $30 \mathrm{a}$ 间, 呼伦湖开始结冰时间平均每阶段 延后 $0.3 \mathrm{~d}$,完全封冻时间平均每阶段延后 $0.2 \mathrm{~d}$,开 始消融时间平均每阶段提前 $1.2 \mathrm{~d}$, 完全消融时间平 均每阶段提前 $1.7 \mathrm{~d}$, 湖冰完全封冻期平均每阶段减 
表 2 1986-2017 年呼伦湖湖冰时间统计

Tab.2 Duration of lake ice cover at the Hulun Lake, 1986-2017

\begin{tabular}{|c|c|c|c|c|c|c|c|c|}
\hline 时间 & 初冰日 & 完全冻结日 & 开始消融日 & 完全消融日 & 湖冰完全封冻期/d & 湖冰存在期/d & 湖冰冻结期/d & 湖冰消融期/d \\
\hline 1986/1987年 & 297 & 301 & $108(+2)$ & $140(+2)$ & 173 & 209 & 5 & 32 \\
\hline 1992/1993 年 & $304(-1)$ & 307 & $102(-1)$ & $127(+1)$ & 162 & 190 & 4 & 26 \\
\hline 1997/1998 年 & $300(-1)$ & $311(-1)$ & $95(-1)$ & 122 & 150 & 188 & 11 & 28 \\
\hline 2002/2003年 & $299(+1)$ & $312(+1)$ & 92 & 136 & 147 & 203 & 12 & 45 \\
\hline 2005/2006年 & 303 & $308(+1)$ & $94(+1)$ & 132 & 152 & 195 & 6 & 39 \\
\hline 2008/2009年 & 305 & 311 & 97 & 129 & 153 & 191 & 7 & 33 \\
\hline 2010/2011年 & 287 & 309 & $99(-1)$ & 127 & 156 & 206 & 23 & 29 \\
\hline 2011/2012年 & 308 & $316(-1)$ & 96 & 132 & 147 & 190 & 9 & 36 \\
\hline 2012/2013年 & 303 & 307 & $99(+2)$ & $137(+1)$ & 159 & 201 & 5 & 38 \\
\hline 2013/2014年 & $310(-1)$ & 318 & 95 & 124 & 143 & 180 & 9 & 30 \\
\hline 2014/2015年 & 308 & $309(+1)$ & 98 & 125 & 155 & 183 & 2 & 28 \\
\hline 2015/2016年 & 307 & 310 & 96 & 123 & 153 & 183 & 4 & 28 \\
\hline 2016/2017年 & $300(+1)$ & 303 & $94(+1)$ & $120(-2)$ & 158 & 187 & 3 & 29 \\
\hline 平均 & 302.3 & 309.4 & 97.3 & 128.8 & 154.5 & 192.8 & 6.4 & 32.2 \\
\hline 阶段平均变幅/d & +0.3 & +0.2 & -1.2 & -1.7 & -0.9 & -2.3 & -0.1 & -0.5 \\
\hline
\end{tabular}

注:误差日期用括号内数字表示,负数代表误差为提前,正数代表误差为延后,以年积日计。误差的主要来源包括:一是实地观测时由于 湖泊面积较大, 目视范围有限, 对于湖泊是否完全冻结或消融有一定的误差; 二是卫星影像由于部分年份数据缺失及某些影像因为质量问题 导致识别和解译出现误差。

少了 $0.9 \mathrm{~d}$ 。相应的冻结期平均每阶段变幅 $0.1 \mathrm{~d}$,表 明冻结时间有缓慢的加快趋势, 而湖冰消融期平均 每阶段提前 $0.5 \mathrm{~d}$, 表明消融时间逐年加快呈明显提 前趋势。与 1986-1987年相比,近 $30 \mathrm{a}$ 呼伦湖湖冰 完全封冻期平均缩短 $18.5 \mathrm{~d}$, 完全结冰时间平均延 后 $8.4 \mathrm{~d}$, 冰全部融化时间平均提前了 $11.2 \mathrm{~d}$ 。其中 2010 - 2011 年比较特殊, 2010 年 10 月 15 日呼伦湖 即出现结冰现象并持续增加冻结面积, 到了 10 月 26 日基本全部封冻,但是在 28 日湖冰开始逐渐融 化且融化面积持续增大, 到 11 月 3 日保持稳定, 次 日开始又出现结冰现象,并在 11 月 6 日完全封冻。 此间, 呼伦湖经历了先结冰后融化再结冰的特殊现 象,这种现象的出现表明了其冰情特征的复杂性 (吴其慧, 2018)。

\section{2 呼伦湖冻融时空过程监测分析}

图 4 显示了 2016-2017 年呼伦湖湖冰冻结消 融过程, 从 2016 年 10 月下旬起到 2017 年 5 月初为 止历时近 7 个月。可以看出呼伦湖在 2016 年 10 月 26 日出现结冰现象且最早开始结冰的区域为湖泊 南部(图 4a), 因为呼伦湖南岸地段湖泊形态较为复 杂且多浅水湾, 所以成为开始结冰最早的区域。随 后从湖东岸开始大面积冻结并迅速向湖西岸延伸,
到 2016年10月 30 日, 湖面已完全冻结(图 4b), 历时 只有短短 $5 \mathrm{~d}$ 便达到封湖状态。呼伦湖这种快速封 冻现象为北方寒区所特有, 历年平均冻结时间为 $6.5 \mathrm{~d}$ (除去特殊的 2010-2011 年), 最快封冻时间为 $2 \mathrm{~d}$ 。湖冰消融通常在 4 月份, 2017 年 4 月 12 日左右 开始出现消融现象(图 4c), 最先开始消融的是湖泊 的北岸与西北区域, 从图 $4 \mathrm{~d}$ 看出湖北岸有明显消融 现象且冰面出现较多裂缝, 到 4 月 27 日湖西北岸已 大面积融化并逐渐向东岸消融(图 4e), 在 4 月 30 日 (图 4f)影像中可以看出东岸的冰也越来越薄, 到 5 月 1 日湖面仅剩部分浮冰(图 $4 \mathrm{~g}$ ), 5 月 3 日全部融化 (图 4h)。

\section{3 湖冰变化与多种因素间的关系}

影响湖泊冰情变化的因素有很多,冰情物候特 征不仅受到区域内气象因素的影响(Dibike et al, 2012), 如累积负积温、风速、风向、太阳辐射、降雪 等(Oveisy et al, 2014), 而且也与湖泊自身的因素有 着很大关系, 如湖水矿化度、湖泊形态因子、湖泊水 深、湖泊面积、湖底地形等; 气温、风速、风向及湖水 矿化度则是影响冰情的主要因子(陶安琪, 2014; 吴 其慧, 2018)。

呼伦湖地处寒旱区, 气候干旱, 寒期较长。通 
(a) 2016-10-26

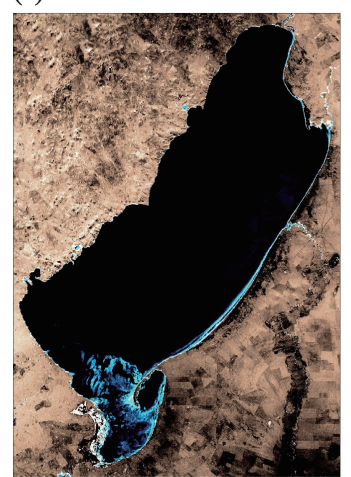

(e) 2017-04-27

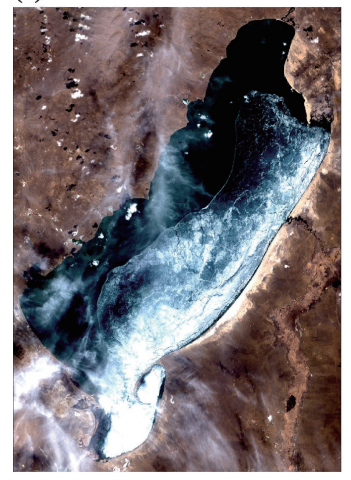

(b) 2016-10-30

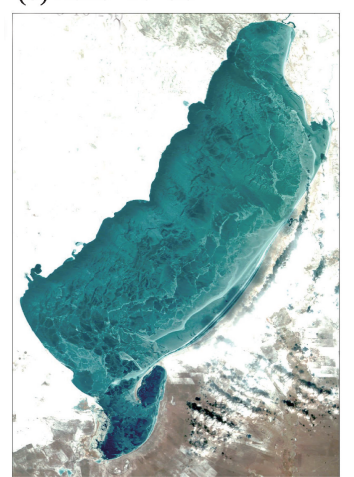

(f) 2017-04-30

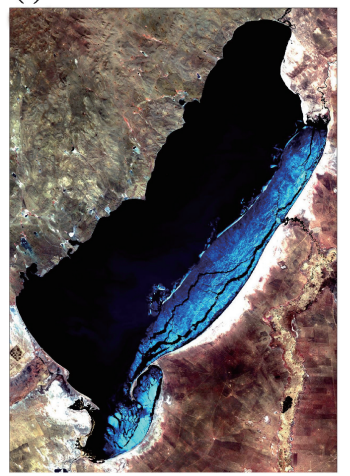

(c) 2017-04-12

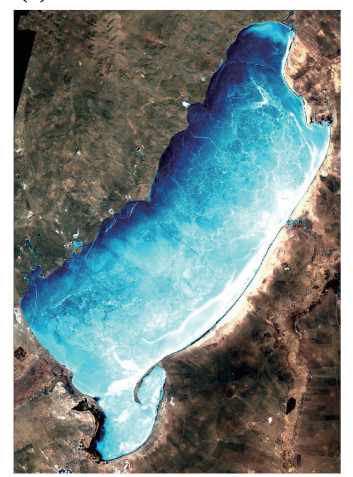

(g) 2017-05-01

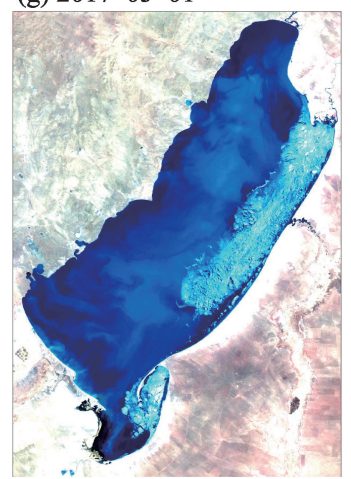

(d) 2017-04-19

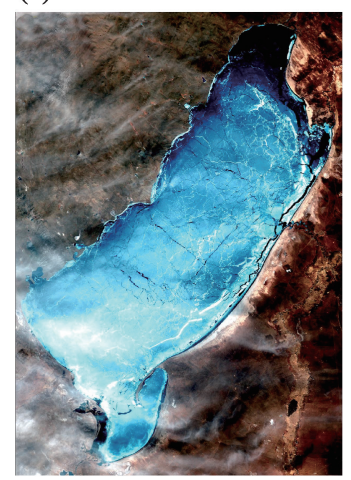

(h) 2017-05-03

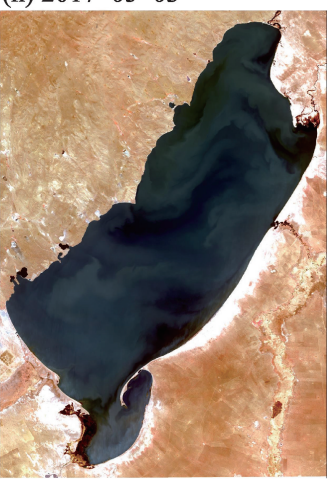

注: 湖面上的蓝色或白色表示湖冰, 黑色为水体, 其他为陆地。

图 4 呼伦湖冻结消融过程

Fig.4 Hulun Lake freezing and melting process

过分析呼伦湖区域内气象站的气温数据(图 5), 可明 显看出气温变化趋势, 呼伦湖地区 40 多年来的平均 气温在 $-2 \sim 4{ }^{\circ} \mathrm{C}$ 之间变化, 1984 年的年均气温为该 时间段内最低温度, 而 2007 年的年均气温则达到该 时间段内最高温度, 就整体变化走势看, 该地区的 温度随时间增加呈现逐渐上升的趋势, 这与全球气 候变暖的趋势一致。为了更详细了解温度变化幅 度,利用分时段来反映变化, 结果表明, 1976-1986 年间平均气温为 $0.74{ }^{\circ} \mathrm{C}, 1987-1997$ 年间平均气温 为 $1.82{ }^{\circ} \mathrm{C}$, 相对于前一个阶段涨幅为 $1.08{ }^{\circ} \mathrm{C}$, 在 1998 - 2008 年间平均温度为 $2.3^{\circ} \mathrm{C}$, 相对于前一阶 段涨幅为 $0.48{ }^{\circ} \mathrm{C}$ 。由此可知呼伦湖地区气温正逐 渐上升(吴其慧, 2018)。

通过分析呼伦湖湖冰冰情特征与区域年均气 温的关系, 可以得到湖冰封冻期随湖区年均气温的 升高而呈现缩短的趋势(图 6a), 即年均气温越高则 湖冰封冻期越短, 相反则越长。图中气温与封冻时 间的变化趋势基本对应良好, 可以明显反映气温的 升高对封冻时间的影响, 由此可知气温是影响湖泊 冰情的主要因素之一。

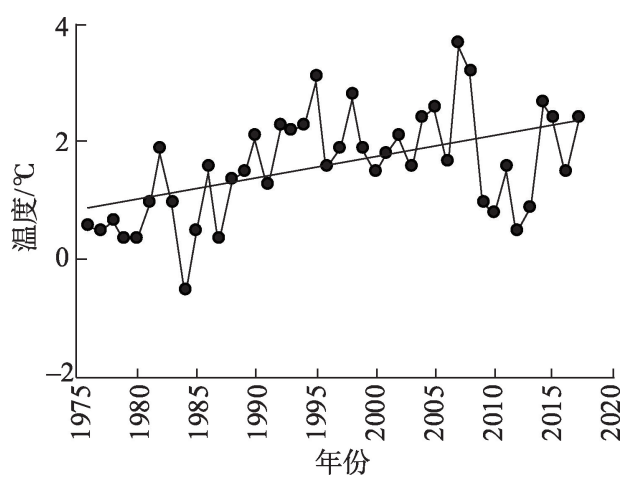

图 5 呼伦湖区域年际温度变化

Fig.5 Interannual temperature variation in the Hulun Lake region

呼伦湖冰情与负积温也有高相关性, 在封冻 期, 累积负积温越大, 呼伦湖封冻天数则越长, 如图 $6 \mathrm{~b}$ 所示, 可明显看出封冻时间与负积温的趋势关 系,但有个别年份(2010年)出现波动幅度较大的现 象,与整体趋势不一致,这是由于该年发生的特别 天气所造成的,而且与其风速也有密切的关系。总 体来看, 负积温与封冻时间表现为较好的负相关, 进一步说明温度是湖冰冰情变化的主要因素。由 

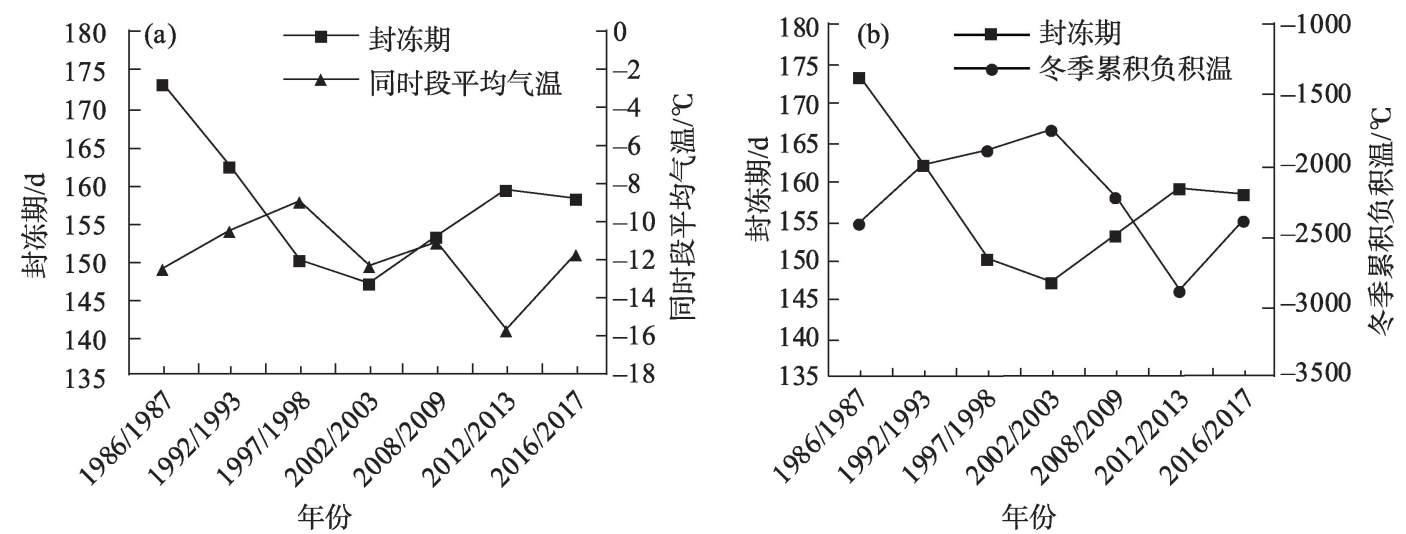

图 6 封冻期与气温间关系

Fig.6 Relationship between freezing period and temperature

极端天气所造成的个别现象需考虑多方面因素(吴 其慧, 2018)。

分析呼伦湖冻结消融过程可以得出, 湖泊完全 冻结时间很短, 往往在很短时间内便完全封冻, 而 湖泊的消融时间相对较长, 平均为 $32 \mathrm{~d}$ 左右。但也 会出现个别极端情况, 如 2010-2011 年出现多次封 冻现象，1997-1998 年和 2002-2003 年封冻时间 则相对较长。分析得知气温和风速是主要影响因 素, 封冻期间如果没有强风浪的出现, 则随着气温 不断下降, 累积负积温不断增加, 湖岸结冰速率会 不断加快并向四周蔓延, 只需几天的时间便可使湖 泊完全冻结。封湖阶段若有风浪, 则会不同, 风浪 带动湖面波动, 湖面处于运动状态会使结冰过程推 迟而影响封湖。湖岸开始结冰后, 冰会因风浪冲击 作用而破裂成块, 并随风吹到湖中心, 由于结冰初 期风力较大且持续时间长, 所以湖中冰块会不断增 加, 同时产生抑制波浪的作用。当冰块面积增加到 一定程度, 风浪难以继续吹散冰层, 湖面就大面积 冻结,遂实现全湖封冻(吴其慧, 2018)。消融期间， 随气温升高, 消融速率加快, 而 4 月、 5 月是呼伦湖 区域风速年内最大的时间段,大风天气使得开始融 化的湖冰更加脆弱, 会被风吹散吹乱并形成较多较 大的冰面裂缝, 从而加快了湖冰的消融速率。

从风速上分析, 对湖冰冰情造成影响的主要有 2 个方面: 一方面是风速较大时会加快湖面空气对 流, 使湖面降温更加明显, 带走湖冰形成时所产生 的热量, 使湖冰冻结和增厚的速率明显加快, 同时 也加快了湖泊封冻的时间; 另一方面是风速增大的 同时, 其动力作用常常会吹乱和破坏已冻结好的湖 冰, 从而对湖冰的冻结起到延缓作用(曲斌等,
2012; 吴其慧, 2018), 在湖面结冰初期与末期二者 的影响力度不同。总体来说, 风速越大, 结冰速率 越快的趋势更加明显。在消融期内风速越大湖冰 的消融速率也就越快。统计气象资料显示, 呼伦湖 地区冬季期间盛行西北风 (王苏民, 1998; 汪敬忠 等, 2015), 强风天气对于结冰初期的速率起到促进 作用, 使得呼伦湖在短时间内快速结冰。而在融冰 期间, 强风天气则会加快湖冰的融化, 风速越大则 湖水动力越大, 造成的风浪越大, 对于开始融化的 湖冰有着强大的冲力作用, 使其融化速度加快 (吴 其慧, 2018)。

根据历年气象数据, 统计分析了结冰及融冰时 间关键点前后的气象因子变化。如图 7, 选取了冻 融时间点前后共 1 周的风速变化情况来研究其相关 性。从图 7 中可以明显看出周内风速与完全结冰时 间及开始融冰时间的变化趋势。从图 $7 \mathrm{a}$ 可看出完 全结冰时间与周内风速的关系,在周内风速较大的 年份, 湖冰冻结的时间越早, 相反, 在周内风速较小 的年份, 湖冰冻结的时间则相对较晚; 从图 $7 \mathrm{~b}$ 可看 出开始融冰时间与周内风速的关系, 当周内风速较 大时, 湖冰的消融时间则越早, 相反, 当周内风速较 小时,湖冰消融时间则较晚(吴其慧, 2018)。

图 8 为呼伦湖岸边气象站 2012/2013/2014 年 4 月份(融冰期)及 11 月份(冻结期)的月内风向变化趋 势。可以看出,整个湖区无论在冻结期或者消融期 内风向都以西北风为主要风向, 且发生频率较高, 又以每年的 4 月份最为明显。由历年统计资料得知 湖区冬季期间西北风频发且风力较大, 与文中数据 分析得到的结果相关性一致。由于冬季期间大风 天气较多且以西北风为主, 导致呼伦湖西北岸一带 

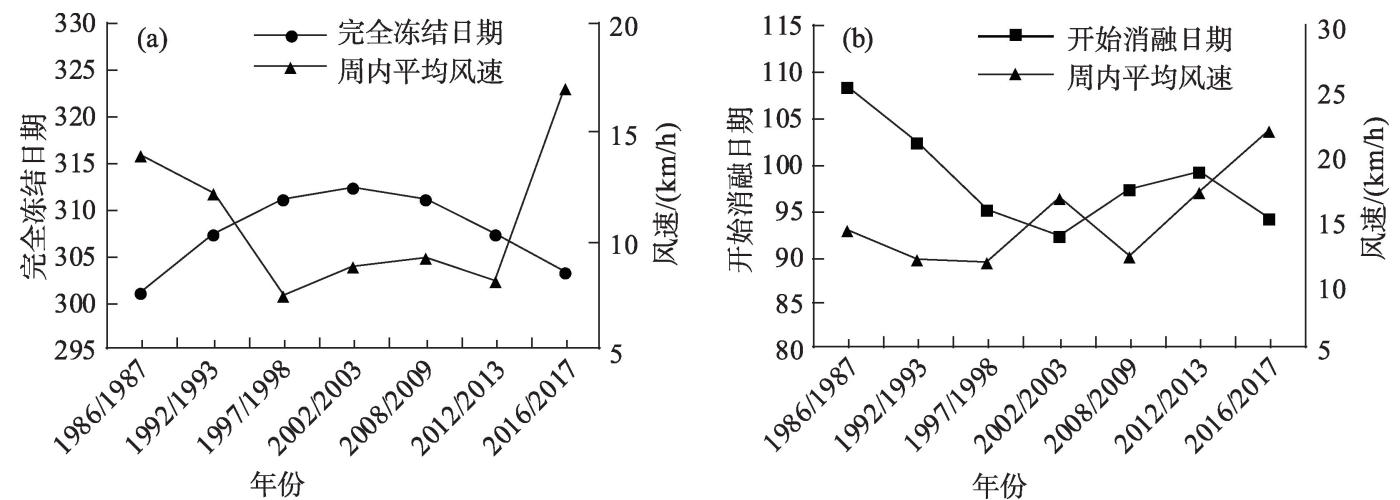

图 7 周内平均风速与冰情物候特征关系

Fig.7 Relationship between weekly mean wind speed and complete freezing time
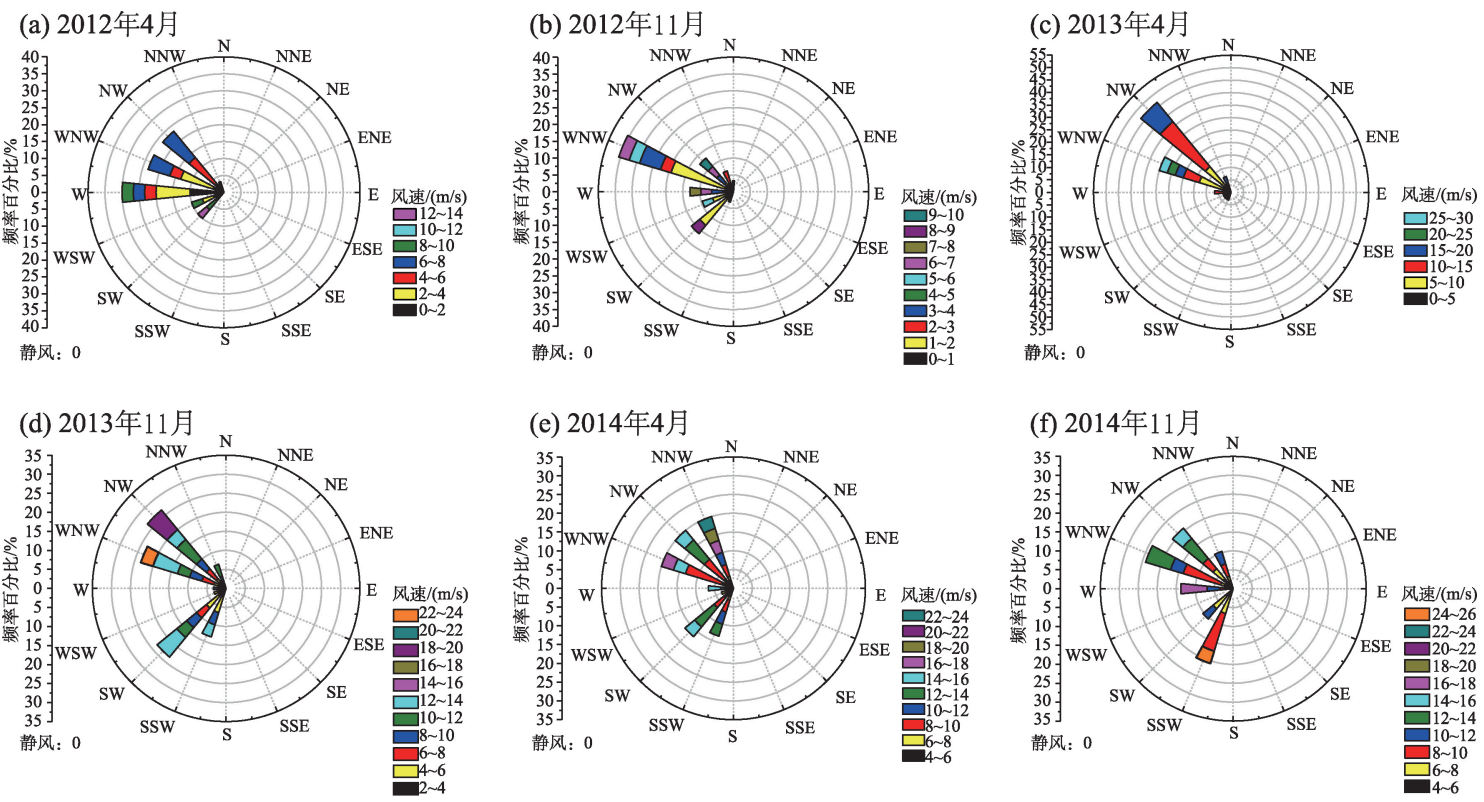

图 8 关键期内风向风速变化趋势

Fig.8 Wind direction and velocity change trend in critical periods

在初冰期刚结的冰被风吹到东南岸并大量累积,所 以从影像上看湖东岸较西岸结冰早。同时在融冰 期由于西北风的影响, 使得北岸和西北岸的冰快速 融化, 而东岸的冰融化则相对较慢。

\section{4 结论}

本文研究结果表明, 1986-2017年间, 呼伦湖 完全结冰时间延后, 完全消融时间提前, 完全封冻 时间缩短。呼伦湖冰情受到多种因素的影响,包括 气温、风速、风向及其自身的因素(湖泊形状等)。其 中, 气温对冰情的影响力最大, 通过气象资料分析 得知, 近 $30 \mathrm{a}$ 间, 湖区温度明显升高, 且冬季累积负
积温有一定下降趋势。此外,风速风向方面对冰情 也有较大影响。湖区冬季期间西北风盛行, 且多大 风天气, 尤以 11 月和 4 月份最为显著, 这直接影响 湖冰的冻结和消融。经过分析, 主要得到以下结论:

(1) 呼伦湖通常在每年 10 月底到 11 月初开始 结冰,冻结时间很短, 仅需短短几天湖面就会完全 封冻, 次年 4 月上旬开始消融, 至 5 月初湖冰全部融 化。呼伦湖平均湖冰存在期为 $192.8 \mathrm{~d}$, 平均湖冰完 全封冻期为 $154.5 \mathrm{~d}$, 平均湖冰冻结期为 $6.4 \mathrm{~d}$, 平均 湖冰消融期为 $32.2 \mathrm{~d}$ 。近 $30 \mathrm{a}$ 呼伦湖湖冰完全封冻 期平均缩短 $18.5 \mathrm{~d}$, 完全结冰时间平均延后 $8.4 \mathrm{~d}$, 冰 全部融化时间平均提前了 $11.2 \mathrm{~d}$ 。

(2) 从呼伦湖冻结空间模式上看, 湖面通常从 
湖岸形态较为复杂的区域开始结冰, 然后湖泊东岸 随之冻结并迅速蔓延至湖泊西岸达到完全封冻, 冻 结速率很快。消融则是从湖泊北岸和西北岸开始 率先融化, 逐步向湖东岸消融直至完全解冻, 相对 而言, 湖冰消融速率则要慢很多。

(3) 在气温影响方面, 当累积负积温越大时, 湖 冰冻结速率越快, 结冰越早, 且封冻期也越长。在 风速风向影响方面, 西北风主要集中在冬季, 11 月 及 4 月最为明显。在冰形成初期, 风速可以使湖面 快速降温, 加快湖面封冻; 在融冰期间, 风速往往为 年内最大值, 使得湖面融化速率加快。其他因素方 面, 湖泊形态越复杂则湖泊越容易结冰, 结冰时间 也越早。

(4) 呼伦湖湖冰冰情作为气候指示器能够很好 地反映区域内的气候变化, 对气温方面的变化反映 较为明显。

\section{参考文献(References)}

白照广. 2013. 高分一号卫星的技术特点 [J]. 中国航天, (8): 5-9. [Bai Z G. 2013. Technical characteristics of Gaofen-1 satellite. Chinese Space, (8): 5-9. ]

车涛, 李新, 晋锐. 2009. 利用被动微波遥感低频亮温数据监 测青海湖封冻与解冻期 [J]. 科学通报, 54(6): 787-791. [Che T, Li X, Jin R. 2009. Monitoring the frozen duration of Qinghai Lake using satellite passive microwave remote sensing low frequency data. Chinese Science Bulletin, 54 (6): 787-791. ]

勾鹏, 叶庆华, 魏秋方. 2015. 2000-2013 年西藏纳木错湖冰 变化及其影响因素 [J]. 地理科学进展, 34(10): 12411249. [Gou P, Ye Q H, Wei Q F. 2015. Lake ice change at the Namco Lake on the Tibetan Plateau during 2000-2013 and influencing factors. Progress in Geography, 34(10): 1241-1249. ]

韩知明, 贾克力, 赵胜男, 等. 2017. 呼伦湖冰封期与非冰封 期营养盐与离子分布特征研究 [J]. 生态环境学报, 26 (7): 1201-1209. [Han Z M, Jia K L, Zhao S N, et al. 2017. Distribution characteristics of the nutrients and ion of $\mathrm{Hu}-$ lun Lake in frozen and unfrozen period. Ecology and Environmental Sciences, 26(7): 1201-1209. ]

祁苗苗, 姚晓军, 李晓锋, 等. 2018. 2000-2016年青海湖湖 冰物候特征变化 [J]. 地理学报, 73(5): 932-944. [Qi M M, Yao X J, Li X F, et al. 2018. Spatial-temporal characteristics of ice phenology of Qinghai Lake from 2000 to 2016. Acta Geographica Sinica, 73(5): 932-944. ]

秦大河. 2012. 中国气候与环境演变: 2012 综合卷 [M]. 北
京: 气象出版社. [Qin D H. 2012. Climate and environment change in China: 2012 comprehensive volume. Beijing, China: China Meteorological Press. ]

曲斌, 康世昌, 陈锋, 等. 2012. 2006-2011 年西藏纳木错湖 冰状况及其影响因素分析 $[\mathrm{J}]$. 气候变化研究进展, 8(5): 327-333. [Qu B, Kang S C, Chen F, et al. 2012. Lake ice and its effect factors in the Nam Co Basin, Tibetan Plateau. Progressus Inquisitiones de Mutatione Climatis, 8(5): 327-333. ]

孙标. 2010. 基于空间信息技术的呼伦湖水量动态演化研究 [D]. 呼和浩特: 内蒙古农业大学. [Sun B. 2010. The dynamic change of water based on spatial information technology for Hulun Lake in Inner Mongolia. Huhhot, China: Inner Mongolia Agricultural University. ]

陶安琪. 2014. 被动微波遥感纳木错湖冰变化研究 [D]. 南 京: 南京大学. [Tao A Q. 2014. Research on the variation of Namco Lake ice by passive microwave remote sensing. Nanjing, China: Nanjing University. ]

汪敬忠, 吴敬禄, 曾海鳌, 等. 2015. 内蒙古主要湖泊水资源 及其变化分析 $[\mathrm{J}]$. 干早区研究, 32(1):7-14. [Wang J Z, Wu J L, Zeng H A, et al. 2015. Changes of Water resources of the Main Lakes in Inner Mongolia. Arid Zone Research, 32(1): 7-14. ]

王桥, 吴传庆, 厉青. 2010. 环境一号卫星及其在环境监测中 的应用 [J]. 遥感学报, 14(1): 113-126. [Wang Q, Wu C Q, Li Q. 2010. Environment satellite 1 and its application in environmental monitoring. Journal of Remote Sensing, 14 (1): 113-126. ]

王苏民. 1998. 中国湖泊志 [M]. 北京: 科学出版社. [Wang S M. 1998. China lakes record. Beijing, China: Science Press. ]

王智颖, 吴艳红, 常军, 等. 2017. 青藏高原湖冰物候的时空 变化及其影响因素 [J]. 北京工业大学学报, 43(5): 701709. [Wang Z Y, Wu Y H, Chang J, et al. 2017. Temporal and spatial variation of lake ice phenology and its influencing factors in the Tibetan Plateau. Journal of Beijing University of Technology, 43(5): 701-709. ]

魏秋方, 叶庆华. 2010. 湖冰遥感监测方法综述 [J]. 地理科学 进展, 29(7): 803-810. [Wei Q F, Ye Q H. 2010. Review of lake ice monitoring by remote sensing. Progress in Geography, 29(7): 803-810. ]

吴其慧. 2018. 基于遥感影像的呼伦湖湖冰近 30 年的变化分 析及其影响因素研究 [D]. 呼和浩特: 内蒙古农业大学. [Wu Q H. 2018. Study on the variation of Hulun Lake ice in recent 30 years and its influencing factors based on remote sensing image. Huhhot, China: Inner Mongolia Agri- 
cultural University. ]

徐占江. 1989. 呼伦湖志 [M]. 吉林: 吉林文史出版社. [Xu Z

J. 1989. Records of Hulun Lake. Jilin, China: Jilin Literature and History Press. ]

殷青军, 杨英莲. 2005. 基于 EOS/MODIS 数据的青海湖遥感 监测 [J]. 湖泊科学, 17(4): 356-360. [Yin Q J, Yang Y L. 2005. Remote sensing monitoring of Lake Qinghai basedon EOS/MODIS data. Journal of Lake Sciences, 17(4): 356-360. ]

姚晓军, 李龙, 赵军, 等. 2015. 近 10 年来可可西里地区主要 湖泊冰情时空变化 [J]. 地理学报, 70(7): 1114-1124. [Yao X J, Li L, Zhao J, et al. 2015. Spatial-temporal variations of lake ice in the Hoh Xil region from 2000 to 2011. Acta Geographica Sinica, 70(7): 1114-1124. ]

Benson B J, Magnuson J J, Jensen O P, et al. 2012. Extreme events, trends, and variability in Northern Hemisphere lake-ice phenology (1855-2005) [J]. Climatic Change, 112 (2): 299-323.

Cai Y, Chang Q K, Li X, et al. 2019. Variations of lake ice phenology on the Tibetan Plateau from 2001 to 2017 based on MODIS Data [J]. Journal of Geophysical Research: Atmospheres, 124(2): 825-843.

Cheng A, Ruth P. 2013. An ice-ocean coupled model for the Northern Hemisphere [J]. Geophysical Research Letters, 19 (9): 901-904

Dibike Y, Prowse T, Bonsal B, et al. 2012. Simulation of North American lake ice cover characteristics under contemporary and future climate conditions [J]. International Journal of Climatology, 32(5): 695-709.

Duguay C R, Prowse T D, Bonsal B R, et al. 2010. Recent trends in Canadian lake ice cover [J]. Hydrological Processes, 20(4): 781-801.

Hodgkins G A, Ii I C J, Huntington T G. 2002. Historical changes in lake ice- out dates as indicators of climate change in New England, 1850-2000 [J]. International Journal of Climatology, 22(15): 1819-1827.

Howell S E L, Brown L C, Kang K K, et al. 2009. Variability in ice phenology on Great Bear Lake and Great Slave Lake, Northwest Territories, Canada, from SeaWinds/Qui-
kSCAT: 2000-2006 [J]. Remote Sensing of Environment, 113(4): 816-834.

Kour R, Patel N, Krishna A P. 2015. Assessment of relationship between snow cover characteristics (SGI and SCI) and snow cover indices (NDSI and S3) [J]. Earth Science Informatics, 8(2): 317-326.

Kropáček J, Maussion F, Chen F, et al. 2013. Analysis of ice phenology of lakes on the Tibetan Plateau from MODIS data [J]. Cryosphere, 7(1): 287-301.

Latifovic R, Pouliot D. 2007. Analysis of climate change impacts on lake ice phenology in Canada using the historical satellite data record $[\mathrm{J}]$. Remote Sensing of Environment, 106(4): 492-507.

Magnuson J J, Robertson D M, Benson B J, et al. 2000. Historical trends in lake and river ice cover in the northern hemisphere [J]. Science, 289: 1743-1746.

Oveisy A, Boegman L, Imberger J. 2014. Three-dimensional simulation of lake and ice dynamics during winter [J]. Journal of Limnology, 73(3): 43-57.

Pachauri R, La M. 2014. IPCC 2014: Climate change 2014: Synthesis report. Contribution of Working Groups I, II and III to the fifth assessment report of the intergovernmental panel on climate change [J]. Journal of Romance Studies, 4 (2): $85-88$

Stocker T F, Qin D, Plattner G K, et al. 2014. Climate change 2013: The physical science basis. Contribution of working group I to the fifth assessment report of IPCC the intergovernmental panel on climate change [M]. Cambridge, UK: Cambridge University Press.

Weber H, Riffler M, Nõges T, et al. 2016. Lake ice phenology from AVHRR data for European lakes: An automated twostep extraction method [J]. Remote Sensing of Environment, 174: 329-340.

Weyhenmeyer G A, Meili M, Livingstone D M. 2012. Nonlinear temperature response of lake ice breakup [J]. Geophysical Research Letters, 31(31): 157-175.

Zhang G Q, Xie H J, Yao T D, et al. 2013. Water balance estimates of ten greatest lakes in China using ICESat and Landsat data [J]. Chinese Science Bulletin, 58(31): 3815-3829. 


\title{
Change of ice phenology in the Hulun Lake from 1986 to 2017
}

\author{
WU Qihui, LI Changyou, SUN Biao*, SHI Xiaohong, ZHAO Shengnan, HAN Zhiming \\ (Water Conservancy and Civil Engineering College, Inner Mongolia Agricultural University, Hohhot 010018, China)
}

\begin{abstract}
Lake ice phenology is a sensitive indicator of climate change. This study examined lake ice phenology of the Hulun Lake in Inner Mongolia, China based on multi-source remote sensing imageries including MODIS, Landsat, GF-1, and HJ-1 and meteorological data. We used GIS technology to comprehensively analyze the phenological characteristics of ice in the Hulun Lake and its response to regional climate from 1986 to 2017. The results show that: 1) The average freezing time of the Hulun Lake began in late October to early November, and the average time from freezing to complete freezing was 6.4 days. The melting start was usually in early April of the following year, and the ablation period averaged about 32 days. At the beginning of early May, the lake ice completely melted. 2) From 1986 to 2017, the complete freezing period of the Hulun Lake showed a significant shortening trend, with an average shortening of 18.5 days. The complete freezing time showed some delay, with an average delay of 8.4 days. The complete ice melting time advanced, with an average advancement of 11.2 days. 3) The spatial characteristics of freezing and melting of lake ice are different. Freezing starts from the complex shoreline areas of the lake, then rapidly propagate from the east coast to the west coast, but melting starts from the northwest coast of the lake and gradually spread toward the east shore. 4) The characteristics of ice conditions in the Hulun Lake are mainly affected by regional air temperature, wind speed, wind direction, among other factors.
\end{abstract}

Keywords: lake ice; multi-source remote sensing; temporal and spatial changes; phenology; Hulun Lake 